Kong. Res. J. 2(1) : 53-55, 2015

ISSN 2349-2694

Kongunadu Arts and Science College, Coimbatore.

\title{
ANTIMICROBIAL ACTIVITY OF SYZYGIUM GARDNERI ThW. (MYRTACEAE).
}

\author{
Asha devi, V., A. Shalimol*, K. Arumugasamy, R. Nantha kumar and H. Abdul kaffoor \\ PG and Research Department of Botany, Kongunadu Arts and Science College, Coimbatore-641029. \\ *Email id: shalimol.anamika@gmail.com
}

\begin{abstract}
The present study was evaluated the antibacterial and antifungal activity of various extracts of $S$. gardneri against four different bactria and fungal strains like Bacillus subtilis, Escherichia coli, Pseudomonas aeruginosa, Salmonella para typhi b. Alternaria alternate, Aspergillus flavus, Penicillium notatum and Cladosporium carrionii. All the results were compared with respective positive control.
\end{abstract}

Keywords: Syzygium gardneri, antimicrobial activity.

\section{INTRODUCTION}

Infectious diseases account for high proportion of health problems in the developing countries like India. Microorganisms have developed resistance to many antibiotics and created immense clinical problem in the treatment of infectious diseases. The resistance of the organism increased due to the indiscriminate use of commercial antimicrobial drugs commonly used.This situation forced the scientist to search for new antimicrobial substances from various sources including medicinal plants (Sashikumar et al., 2003). However several plants are used in India in the form of crude extracts, infusions or plaster to treat common infections without scientific evidence of efficacy (Ahmad et al., 1998).

In India, the floristic accounts suggest that Syzygium gardneri occur evergreen forests in the country. It is used in treatment of diabetes mellitus, inflammation, ulcers and diarrhea, dysentery possessing also anti-neoplastic, chemopreventive and radio-protective properties. The seeds and bark are well known in the Far East for the treatment of dysentery and in control of hyperglycemia and glycosuria in diabetic patients. The astringent bark may be used as a gargle. Fruits are used as a relief for colic, while the wood yields a sulphate pulp that has medicinal uses.

\section{MATERIALS AND METHODS}

\subsection{Plant collection and identification}

The Plant Syzygium gardneri Thw. was collected from Valparai, Coimbatore district, Tamilnadu. The plant was identified and authenticated by a plant taxonomist.

\subsection{Extraction of the plant material}

$250 \mathrm{~g}$ of freshly collected sample of Syzygium gardneri (leaf and bark) was separately washed 2-3 times with water followed by distilled water and shade dried. All the dried parts were pulverized by mechanical grinder (willey mill) to get the powder through 100 mess sieve and then stored in a refrigerator. It was extracted by cold extraction method with petroleum ether, ethanol, methanol and aqueous. Then all the extracts were concentrated in a rotary evaporator to yield a syrupy residue and used for all the phytochemical analysis.

\subsection{Tested Microorganisms}

Bacterial strains Bacillus subtilis, Escherichia coli, Pseudomonas aeruginosa, Salmonella para typhi $b$, and fungal strains Alternaria alternate, Aspergillus flavus, Cladosporium carrionii, and Penicillium notatum, were employed.

\subsection{Disc diffusion method}

The antimicrobial activity of leaves and bark extracts of Syzygium gardneri was evaluated by disc diffusion method. The culture media were prepared and autoclaved at $121^{\circ} \mathrm{C}$ at $15 \mathrm{psi}$ for 20 minutes and stored in refrigerator. The media were melted before the process of inoculation. The clean dry sterile Petri dishes were poured with nutrient agar medium for bacterial strains and potato dextrose agar medium for fungal strains. Ten number of $10 \mathrm{ml}$ broths were prepared separately for nutrient agar medium and potato dextrose agar medium in test tubes and plugged with cotton and autoclaved. The test tubes were labelled according to the microbes to be inoculated. The bacterial strains were inoculated into the nutrient broth and fungi were inoculated on to potato dextrose broth under aseptic conditions and incubated at $37+0.5^{\circ} \mathrm{C}$ for 18 hours. After 
incubation, the bacteria and fungi were smeared on the nutrient agar and potato dextrose agar plate respectively using a sterile cotton swab. A sterile disc of $6 \mathrm{~mm}$ diameter was loaded with known quantity of $10 \mathrm{mg}$ of dried crude extracts of aqueous, petroleum ether, ethanol and methanol extracts and dissolved in $10 \mathrm{ml}$ of DMSO. These discs were placed on the surface of the media. The positive control antibiotics viz., chloramphenical for fungi $(10 \mu \mathrm{g})$ were maintained. Then the Petri dishes were incubated at $37+0.5^{\circ} \mathrm{C}$ for 12 to 14 hours. The diameters of inhibition zones were measured (Bauer et al.,1966).

\section{RESULTS}

Aqueous, petroleum ether, ethanol and methanol extracts of $S$. gardneri was assessed for antimicrobial (Table-1).The results showed that among the four extracts, methanol showed significant result of antibacterial activity. When compared with other extracts, aqueous extract showed minimum level of inhibition. Among the seven bacterial strains, maximum zones were observed in the following bacterial strains such as $B$. subtilis, $P$. aeruginosa and E. coli., S. paratyphi- $b$ were found to be highly susceptible to methanol extract. The inhibition zone of methanol extract was similar to that of the control, chloramphenical.

The results of fungal study showed that among the four extracts, methanol showed significant result of antifungal activity. The results of the extracts, aqueous extract showed minimum level of inhibition. In vitro anti-fungal studies of different solvent extracts of $S$. gardneri revealed that the methanol extract had significant activity against most of the organism tested (Table-2). Methanol extract has

exhibited the maximum inhibitory effect against fungal strain, $A$. alternata and moderate activity against $A$. flavus and $P$. notatum. Whereas, in aqueous extract has no activity. The positive control chloramphenical showed highest activity against all organisms tested. C. carrionii found to be highly susceptible to methanol extract.

\section{DISCUSSION}

The results showed that the aqueous, petroleum ether, ethanol and methanol extracts of Syzygium gardneri has revealed a significant results of antibacterial activity when compared with other extracts except aqueous showed minimum level of inhibition. Among all the bacterial strains, maximum zones were observed in the following bacterial strains such as B.subtilis, P. aeruginosa and E. coli. $S$. paratyphi- $b$ were found to be highly susceptible to methanol extract. Plant extracts are potential sources of novel anti-microbial compounds especially against bacterial pathogens. Phytomedicine can be used for the treatment of diseases as in case of Unani and Ayurvedic system of medicine or it could be the base for the development of medicine, a natural blue print for the development of a drug (Didry et al., 1988).

In Myrtaceae, family plants showed the efficient antimicrobial effect on microbial organisms. The anti-microbial activity of ethanol, methanol and aqueous extracts of leaf, stem and root of Acanthus ilicifolius were studied the strains like Bacillus megaterium, Lactobacillus plantarum, Salmonella paratyphi B, Shigella dycentreae, Escherichia coli, Streptococcus mutans, Klebsiella pneumoniae, Candida albicans, Aspergillus flavus, Staphylococcus albus and Lactobacillus acidophilus, revealed that the solvent used in extractions had significant effect on the level of significant. Aqueous and acetone extracts of bark, leaves and seeds of Syzygium jambos was tested for anti-microbial activity in vitro by the agar well diffusion method in petri dishes. Both extracts showed moderate activity against all the tested microorganisms. Among the three different parts, aqueous extract of bark has exhibited a minimum inhibitory effect against $S$. aureus, E. coli and S. typhi, whereas seeds inhibited the growth of $P$. aeruginosa and $V$. cholerae, and leaves exhibited inhibitory effect only against $S$. typhi. Among the acetone extracts, bark was found to be effective against the entire test microorganisms. Leaf extract has inhibited only $S$. aureus, whereas seed extracts failed to exhibit any inhibitory effect against the test organisms (Murugan et al., 2011).

\section{Table 1. Antibacterial activity of various solvent extracts of Syzygium gardneri.}

\begin{tabular}{clccccc}
\hline & & \multicolumn{5}{c}{ Zone of Inhibition (mm) } \\
\cline { 3 - 6 } $\begin{array}{c}\text { S. } \\
\text { No. }\end{array}$ & Microorganisms & \multicolumn{5}{c}{ Various solvent } \\
extracts used (mg/ml) & Control* \\
\cline { 3 - 6 } & & $\mathbf{A}$ & PE & E & M & \\
\hline 1 & Bacillus subtilis & 10 & 11 & 11 & 13 & 15 \\
2 & $\begin{array}{l}\text { Escherichia coli } \\
3\end{array}$ & 10 & 12 & 11 & 12 & 14 \\
$\begin{array}{l}\text { Pseudomonas } \\
\text { aeruginosa }\end{array}$ & 9 & 10 & 10 & 12 & 16 \\
4 & $\begin{array}{l}\text { Salmonella para } \\
\text { typhi b }\end{array}$ & 8 & 10 & 9 & 11 & 12 \\
\hline
\end{tabular}

A-Aqueous; PE-Petroleum Ether; E-Ethanol; M-Methanol;

*Chloramphenical

In vitro anti-fungal studies of different solvent extracts of Syzygium gardneri revealed that the methanol extract had significant activity against most of the organism tested. Methanol extract exhibited the maximum inhibitory effect against fungal strain, Alternaria alternata and moderate activity against A.flavus and P.notatum. The positive control chloramphenical showed highest activity 
against all organisms tested. C. carrionii found to be highly susceptible to methanol extract.

Table 2. Antifungal activity of various solvent extracts of Syzygium gardneri.

\begin{tabular}{clccccc}
\hline \multirow{2}{*}{$\begin{array}{c}\text { Sl. } \\
\text { No. }\end{array}$} & Microorganisms & \multicolumn{5}{c}{ Zarious solvent } \\
\cline { 3 - 6 } & & extracts used (mg/ml) & Control \\
\cline { 2 - 6 } & & PE & E & M \\
\hline 1 & $\begin{array}{l}\text { Alternaria } \\
\text { alternata }\end{array}$ & 8 & 10 & 10 & 12 & 15 \\
2 & $\begin{array}{l}\text { Aspergillus flavus } \\
\text { Cladosporium }\end{array}$ & 9 & 10 & 10 & 13 & 17 \\
3 & $\begin{array}{l}\text { Carrionii } \\
\text { Penicillium }\end{array}$ & 9 & 11 & 12 & 14 & 16 \\
4 & notatum & 10 & 11 & 11 & 12 & 14 \\
\hline
\end{tabular}

A-Aqueous; PE-Petroleum Ether; E-Ethanol; M-Methanol;

*Chloramphenical

Myrtaceae family plants showed the efficient effect on microbial organisms. The anti-microbial activity of ethanol, methanol and aqueous extracts of leaf, stem and root of Acanthus ilicifolius was studied against different strains like Bacillus megaterium, Salmonella paratyphi-B, Escherichia coli, Candida albicans, Aspergillus flavus, and Lactobacillus acidophilus.The inhibitory effect of the extracts on Lactobacillus acidophillus showed no significant difference $(\mathrm{P}>0.05)$ between extract concentration. The most active anti-microbial parts were aqueous root, ethanol stem and leaf. Aqueous and acetone extracts of bark, leaves and seeds of S. jambos was tested for anti-microbial activity in vitro by the agar well diffusion method. Among the three different parts, aqueous extracts of bark have exhibited a minimum inhibitory effect against $S$. aureus, E. coli and S. typhi, whereas seeds inhibited the growth of $P$. aeruginosa and $V$. cholerae, and leaves exhibited inhibitory effect only against $S$. typhi. Among the acetone extracts, bark was found to be effective against the entire test microorganisms. Leaves inhibited only $S$. aureus, whereas seed extracts failed to exhibit any inhibitory effect against the test

organisms (Murugan et al., 2011).

\section{REFERENCES}

Ahmad, I., Z. Mehmood and F. Mohammad, (1998). Screening of some Indian medicinal plants for their antimicrobial properties. J. Ethanopharmacol. 62:183-193.

Bauer, A.W., W.M.M. Kirby, J.C. Sherris and M. Turck, (1966). Anti-biotic susceptibility testing by a standardized single disk method. Am. J. Clin. Pathol. 45: 493-496.

Didry, N., L. Dubreuil, F. Trotin and M. Pinkas, (1988). Anti-microbial activity of the aerial parts of Drosera pellata smith on oral bacteria. J. Ethnopharmacol. 60: 91-96.

Murugan, S., P. Uma Devi, N. Kannika Parameswari and K.R. Mani. (2011). Anti-microbial activity of Syzygium jambos against selected human pathogens. Int. J. Pharm. Sci. 3(2): 44-47.

Sashikumar, J.M., M. Remya and K. Janardhanan, (2003).Antimicrobial activity of ethanol medicinal plants of Nilgiri Bioshpere reserve and Western Ghats. Asian J. Microbial. Biotechnol. 5: 183-185. 